\title{
PENGEMBANGAN MEDIA PEMBELAJARAN SEGIEMPAT BERBASIS ADOBE FLASH CS6 MELALUI PENDEKATAN CONTEXTUAL TEACHING AND LEARNING UNTUK MEMFASILITASI KEMAMPUAN KONEKSI MATEMATIS
}

\author{
Fera Yuniar $^{1)}$, Sumarni ${ }^{2)}$, Nuranita Adiastuty ${ }^{3)}$ \\ ${ }^{1), 2), 3)}$ Program Studi Pendidikan Matematika, Universitas Kuningan, Jalan Cut Nyak Dhien \\ No. 36 A Cijoho, Kuningan, Jawa Barat, Indonesia \\ ferakng@gmail.com ${ }^{1)}$,marnie.1205@gmail.com ${ }^{2)}$,anitha_dyaz2@yahoo.co.id ${ }^{3)}$
}

\begin{abstract}
The aims of this research to produce a product in the form of quadrilateral learning media based on Adobe Flash CS6 with a valid Contextual Teaching and Learning approach ti facilitate the mathematical connection ability. This study is the research, development model of plomp with consist of three phase is preliminary research, prototyping phase and assessment phase. The instrument used to data collection in this study were questionnaire of epert validation learning media. The device develoved was validated by three validators including two lecture and one teacher junior high school. From the resulting validation data the average score from three validator is 3,4 which means that the learning media is in the valid category with the value obtained is B which means that the learning media can be used with a little revision

Keywords: Learning Media, Plomp Development Model, Contextual Teaching and Learning, Mathematical Connections Ability
\end{abstract}

\begin{abstract}
Abstrak
Penelitian ini bertujuan mengembangkan media pembelajaran segiempat berbasis Adobe Flash CS6 melalui pendekatan Contextual Teaching and Learning untuk memfasilitasi kemampuan koneksi matematis yang valid. Penelitian ini menggunakan jenis pengembangan model plomp, terdiri dari tiga fase yaitu preliminary research, prototyping phase dan assessment phase. Instrumen yang digunakan untuk mengumpulkan data dalam penelitian ini adalah lembar validasi ahli media pembelajaran. Media pembelajarn yang dikembangkan divalidasi oleh tiga orang validator diantaranya dua orang dosen dan satu orang guru SMP. Dari hasil validasi diperoleh data nilai rata-rata dari ketiga validator adalah 3,4 yang artinya media pembelajaran berada pada kategori valid dengan nilai yang diperoleh adalah B yang berarti media pembelajaran dapat digunakan dengan sedikit revisi..
\end{abstract}

Kata Kunci : Media Pembelajaran, Model Pengembangan Plomp, Contextual Teaching and Learning, Kemampuan Koneksi Matematis

Cara Menulis Sitasi: Yuniar, F., Sumarni, Adiastuty, N. (2020). Pengembangan media pembelajaran segiempat berbasis adobe flash CS6 melalui pendekatan contectual teaching and learning untuk memfasilitasi kemampuan koneksi matematis. Jurnal Edukasi dan Sains Matematika (JES-MAT),6 (2), 101-112. 
Untuk menghadapi persaingan global, dapat dilakukan dengan meningkatkan Sumber daya Manusia-nya salah satu nya dengan memajukan pendidikannya. Hal tersebut sesuai dengan Undang-Undang Republik Indonesia Nomor 20 tahun 2003 (Rahmawati dkk., 2015) yang menyatakan bahwa pendidikan yang baik dapat membangun dan mencerdaskan kehidupan suatu bangsa.

Matematika merupakan mata pelajaran yang penting untuk dipelajari. Hal ini karena menurut Hudoyo (Musriliani dkk., 2015) matematika merupakan dasar ilmu teknologi di dunia yang berperan penting dalam kehidupan nyata. Konsep yang terdapat dalam matematika dapat saling berkaitan, berkaitan dengan ilmu lain dan dengan kehidupan nyata. Kemampuan siswa dalam menyelesaikan masalah tengng keterkaitan matematika merupakan kemampuan koneksi matematis, yang mana merupakan salah satu kemampuan dasar matematika Menurut NCTM (Musriliani dkk., 2015).

Mauliana dkk. (2018) menyatakan bahwa kemampuan koneksi matematis merupakan kemampuan menghubungkan antar topik dalam matematika, hubungan matematika dengan pelajaran lain dan kehidupan sehari-hari sehingga kemampuan ini dinyatakan penting untuk dimiliki setiap siswa. Namun berdasarkan beberapa penelitian seperti hasil survey yang dilakukan Programme for International Student Assessment (PISA) pada tahun 2009 (Organisation for Economic Cooperation and Development (ECO) pada tahun 2010) siswa yang mampu menyelesaikan soal-soal koneksi matematis hanya $5.4 \%$, artinya $94,6 \%$ yang belum mampu menyelesaikan soal dengan benar (Rinzani, 2017)
Pengurangan hasil belajar siswa dalam mengkoneksikan matematis dapat terjadi karena suasana belajar yang monoton karena masih banyaknya guru yang menggunakan metode ceramah dalam pembelajarannya, selain itu juga media yang digunakan masih tergolong lama yang mana masih menggunakan modul cetak dan LKS cetak sehingga menurut Purwanti (2015) dalam pembelajaran siswa cenderung pasif akibatnya media pembelajaran kurang mendapatkan respon yang positif.

Dari pernyataan tersebut diperlukan sebuah media pembelajaran yang sesuai dengan era sekarang yaitu dengan menggunakan teknologi. software yang bisa digunakan untuk membuat media pembelajaran adalah adobe flash CS6, hal ini karena keberhasilan dari penelitian Yuniawati \& Zuhrie (2019) yang menyatakan bahwa media pembelajaran dengan menggunakan adobe flash berada pada kategori valid dengan rating $82 \%$, mendapatkan respon yang baik dari siswa dengan rating $84 \%$ serta mendapatkan ratarata hasil belajar siswa 85 yang artinya penggunaan media pembelajaran dinyatakan efektif digunakan dalam pembelajaran, ia juga menyatakan bahwa adobe flash CS6 merupakan sebuah software yang dapat memuat animasi 2 dimensi yang ringan dan handal.

Berdasarkan Permendikbud Nomor 20 Tahun 2016 tentang Standar Kompetensi Lulusan Pendidikan Dasar dan Menengah, yang menjadi salah satu aspek dari ruang lingkup matematika untuk tingkat SMP/MTs adalah geometri yang mana salah satu materi dari geometri adalah segiempat yang menjadi materi dasar untuk dapat mempelajari materi selanjutnya. Namun, dalam penelitian Jalaludin dkk. 
(2018) hanya 36\% siswa yang dapat menyelesaikan 5 soal koneksi matematis segiempat. Selain itu berdasarkan hasil wawwancara ke salah satu guru di SMP yang ada di Kuningan diketahui bahwa bahwa masih banyak siswa yang mengalami kesulitan dalam menyelesaikan soal-soal yang ada kaitannya dengan kehidupan sehari-hari.

Media pembelajaran berbasis Adobe Flash CS6 dapat dikombinasikan dengan menggunakan pendekatan Contextual Teaching and Learning (CTL) hal ini karena dengan menggunakan CTL siswa dapat berperan aktif dengan menemukan hubungan materi yang dipelajari dalam kehidupan sehari-hari sehingga belajar menjadi lebih bermakna. Hal tersebut sesuai yang dikemukakan oleh Depdiknas (Lestari \& Yudhanegara, 2015) CTL yang merupakan suatu konsep belajar yang dapat membantu guru dalam meghubungkan antara materi dalam pembelajaran dengan kehidupan sehari-hari. Selain itu menurut Widada (2015) penggunaan media pembelajaran kontekstual yang tepat dan sesuai dapat meningkatkan kemampuan siswa dalam proses pencapaian matematika berupa konsep dan prinsip serta meningkatkan ketuntasan belajar siswa. Maka dibutuhkan sebuah media pembelajaran dengan contoh yang terletak pada masing-masing bangun datar segiempat agar siswa tidak mengalami split attention sehingga siswa dapat memahami dengan betul permasalahan untuk setiap bangun datar segiempat.

Berdasarkan uraian di atas, peneliti tertarik untuk melakukan penelitian tentang pengembangan media pembelajaran segiempat berbasis adobe flash cs6 melalui pendekatan CTL dengan kemampuan koneksi matematis.

\section{LANDASAN/KAJIAN TEORI Kemampuan Koneksi Matematis}

Menurut Musriliani dkk. (2015) koneksi matematika merupakan salah satu kemampuan dasar yang dikemukakan oleh NCTM yang menjadi standar. Koneksi matematis berasal dari salah satu kata bahasa Inggris yaitu connection yang artinya hubungan atau kaitan. Sehingga Mathematical connection atau koneksi matematis adalah pengaitan pembelajaran matematika. Nurfitria dkk. (2013) bahwa koneksi matematis adalah kemampuan siswa dalam menghubungkan konsep matematika, matematika dengan bidang lain, dan matematika dalam kehidupan sehari-hari. Dari uraian tersebut dapat disimpulkan bahwa koneksi matematis adalah kemampuan siswa dalam memahami, menghubungkan, dan mengaitkan antar konsep matematika dalam menyelesaikan permasalahan sehari-hari.

Menurut Sumarno (Rinzani, 2017) koneksi matematika terdiri dari 6 indikator, diantaranya: 1) Menemukan hubungan antara konsep dan prosedur, 2) Memahami hubungan antar topik di dalam matematika, 3) Menerapkan matematika dalam bidang studi lain atau dalam kehidupan sehari-hari, 4) Memahami representasi dari konsep yang sama, 5) Menemukan koneksi antara satu prosedur dengan prosedur yang lain dalam representasi yang ekuivalen, dan 6) Menerapkan koneksi antar topik dalam matematika dan antara matematika dengan subjek lain.

\section{Media Pembelajaran}

Secara harfiah media bersal dari kata media yang arinya "tengah, pengantar atau perantara" sedangkan AECT (Association of Education and 
Communication Technology) memberikan batasan terhadap media mengenai segala bentuk saluran yang digunakan dalam menyampaikan suatu informasi (Nugroho, 2011).

Media pembelajaran merupakan salah satu alat yang dapat membantu proses pembelajaran yang bertugas untuk menyalurkan pesan, merangsang pikiran, perhatian dan pengetahuan sehingga pembelajaran dapat berjalan dengan baik. Hal ini sesuai dengan pendapat dari Gagne dan Briggs (Puspita, 2016) yang menyatakan bahwa media pembelajaran dapat berupa bentuk fisik seperti video, film, buku dan sebagainya untuk menyampaikan informasi berupa materi pelajaran. Sedangkan menurut National Education Associaton (Puspita, 2016) menyatakan bahwa media pembelajaran merupakan salah satu alat komunikasi dapat berupa pandang dengar, bentuk cetak serta teknologi.

\section{Adobe Flash CS6}

Yuniawati \& Zuhrie (2019) menyatakan bahwa adobe flash berarti sebuah program khusus oleh adobe dan aplikasi standar authoring tool professional untuk membuat animasi yang handal dan ringan untuk membangun dan memberikan efek animasi serta pembuatan web yang interaktif.

\section{Contextual Teaching and Learning}

Pada tahun 1916, untuk pertama kalinya John Dewey mengusulkan menggunakan pendekatan Contextual Teacing and Learning (CTL) dalam proses pembelajaran yang dikaitkan dalan pengalaman siswa (Panjaitan, 2016). Pendekatan CTL merupakan salah model pembelajaran yang tepat untuk digunakan dalam membantu siswa meningkatkan kemampuan koneksi matematis karena pendekatan CTL erat hubungannya dengan kehidupan sehari-hari karena berdasarkan pengalaman dan siswa dapat terlibat aktif dalam proses pembelajaran. Pembelajaran dengan menggunakan CTL menggunakan komponen CTL yang mana Zaenab (2010) terdapat 7 komponen, diantaranya: 1) Kontruktivisme, 2) Bertanya, 3) Penemuan, 4) Pemodelan, 5) Masyarakat belajar, 6) Penilaian Autentik, dan 7) Refleksi.

\section{METODE PENELITIAN}

\section{Jenis Penelitian}

Penelitian ini menggunakan jenis penelitian pengembangan atau Research and Develovment (R\&D) dengan model pengembangan plomp (Plomp \& Nieveen, 2013).

\section{Waktu dan Tempat Penelitian}

Penelitian pengembangan ini dilaksanakan pada semester genap tahun ajaran 2019-2020 dengan waktu penelitian dari bulsn Desember2019-Agustus 2020.

\section{Prosedur}

Prosedur pengembangan yang digunakan dalam penelitian ini adalah plomp yang terdiri dari 3 fase ((Plomp \& Nieveen, 2013), diantaranya: 1) preliminary research, 2) prototyping phase, 3) assessment phase.Pada fase preliminary research terjadi kegiatan analisis diantaranya analisis kebutuhan untuk mengetahui kebutuhan siswa terhadap media pembelajaran, analisis kurikulum yang bertujuan untuk mengembangkan permasalahan yang tidak sesuai dengan kurikum 2013 dan analisis materi ajar yang disusun secara sistematis.Pada fase prototyping phase yaitu kegiatan mendesian media pembelajaran sesuai dengan pendekatan contextul teaching and 
learning. Dan pada fase assessment pahse yang dilakukan untuk mengukur kevalidan dari media pembelajaran kepada para ahli atau validator.

\section{Data, Intrumen, dan Teknik Pengumpulan Data}

Dalam penelitian ini, untuk mengukur kevalidan data diperoleh dari lembar validasi yang diadopsi dari penelitian Walker \& Hess (Kurnia, 2019) yang dinilai oleh validator.

\section{Teknik Analisis Data}

Teknik analisis data dilakukan setelah data didapatkan. Data didapatkan dari angket yang diberikan kepada validator kemudian dirata-ratakan untuk melihat kevalidan dari media pembelajaran yang dikembangkan. Adapun cara untuk menentukan rata-rata skor dari ketiga validator (Fitrhyah, 2018) adalah sebagai berikut:

a. Mencari rata-rata dari setiap kategori

$$
\boldsymbol{R} K_{i}=\frac{\sum_{j=1}^{n} V_{i j}}{n}
$$

\section{Keterangan:}

$R K_{i}=$ Rata-rata kategori- $i$
$V_{i j}=$ Skor hasil penliaian validator

ke-j terhadap kategori ke- $i$

$\mathrm{n} \quad=$ Banyaknya validator

b. Mencari rata-rata pada tiap aspek dari semua validator

$$
R A_{i}=\frac{\sum_{j=1}^{n} R K_{i j}}{n}
$$

\section{Keterangan:}

$R A_{i} \quad=$ Rata-rata aspek- $i$

$R K_{i j} \quad=$ Skor hasil kategori ke-j terhadap aspek ke- $i$

$\mathrm{n}=$ Banyaknya kategori dalam aspek ke- $i$

c. Mencari rata-rata total validitas

$$
V R=\frac{\sum_{i=1}^{n} R A_{i}}{n}
$$

\section{Keterangan:}

$V R=$ Rata-rata total validitas

$R A_{i}=$ Rata-rata aspek ke- $i$

$\mathrm{n} \quad=$ Banyaknya aspek

Media pembelajaran dikatakan valid apabila rata-rata dari total validasi masuk dalam kategori valid dan sangat valid. Untuk dapat mengetahui kategori kevalidan dari perangkat pembelajaran yang dikembangkan dapat dilihat pada tabel di bawah ini.

Tabel 1. Kriteria Pengkategorian Kevalidan

\begin{tabular}{cc}
\hline Interval Skor & Kategosi Kevalidan \\
\hline $4 \leq V R \leq 5$ & Sangat Valid \\
$3 \leq V R<4$ & Valid \\
$2 \leq V R<3$ & Kurang Valid \\
$1 \leq V R<2$ & Tidak Valid \\
\hline
\end{tabular}

Sumber: Fithryah, 2018

HASIL PENELITIAN DAN mengidentifikasi permasalahan siswa

\section{PEMBAHASAN}

Proses Pengembangan Media

\section{Pembelajaran}

Pada fase preliminary research, peneliti melakukan beberapa analisis diantaranya: analisis kebutuhan yang terkait kurangnya kemampuan dalam mengkoneksikan materi segiempat berdasarkan hasil penelitian terdahulu dan hasil wawancara kepada guru di salah satu SMP di Kuningan. Hal tersebut terjadi karena siswa masih menggunakan media 
pembelajaran yang tergolong lama sehingga menurut Purwanti (2015) dalam pembelajaran siswa cenderung pasif. Dari hal tersebut, peneliti merasa perlu untuk mengembangkan media pembelajaran yang sesuai dengan era sekarang yang berorientasi pada teknologi berbasis adobe flash CS6. Hal ini karena menurut Yuniawati \& Zuhrie (2019) Adobe Flash CS6 dapat membuat animasi yang handal dan ringan dan memberi efek pada sebuah media pembelajaran.

Analisis kurikulum yang mana diketahui bahwa kurikulum yang yang berlaku kurikulum 2013. Namun faktanya diketahui bahwa pembelajaran yang dilakukan oleh guru masih menggunakan metode ceramah yang pembelajarannya beriorientasi pada guru (teacher centre). Hal tersebut tidak sesuai dengan Permendikbud Nomor 35 Tahun 2018 yang menyatakan bahwa kurikulum 2013 diterapkan untuk menyempurnakan pola pikir siswa sehingga pembelajaran berpusat pada siswa (student centre).
Analisis materi yang dilakukan oleh peneliti, materi segiempat dipilih karena merupakan materi dasar untuk dapat mempelajari materi selanjutnya. Selain itu, berdasarkan penelitian Jalaludin dkk. (2018) masih banyak siswa yang mengalami kesalahan dalam menyelesaikan soal koneksi matematika terkait luas dan keliling pada bangun persegi panjang yang mana dari 5 orang siswa yang ada hanya 2 orang siswa yang mampu menyelesaikan soal.

Pada fase prototyping phase dilakukan desain media pembelajaran yang disesuaikan dengan pendekatan CTL dengan kemampuan koneksi matematis. Adapun hasil perancangan media pembelajaran adalah sebagai berikut:

Konstruktivisme merupakan keterlibatan siswa dalam pembelajaran. Gambar di bawah ini adalah kegiatan siswa dalam mengkonstruksi pengetahuan dalam mencari segiempat dengan cara mengetuk.

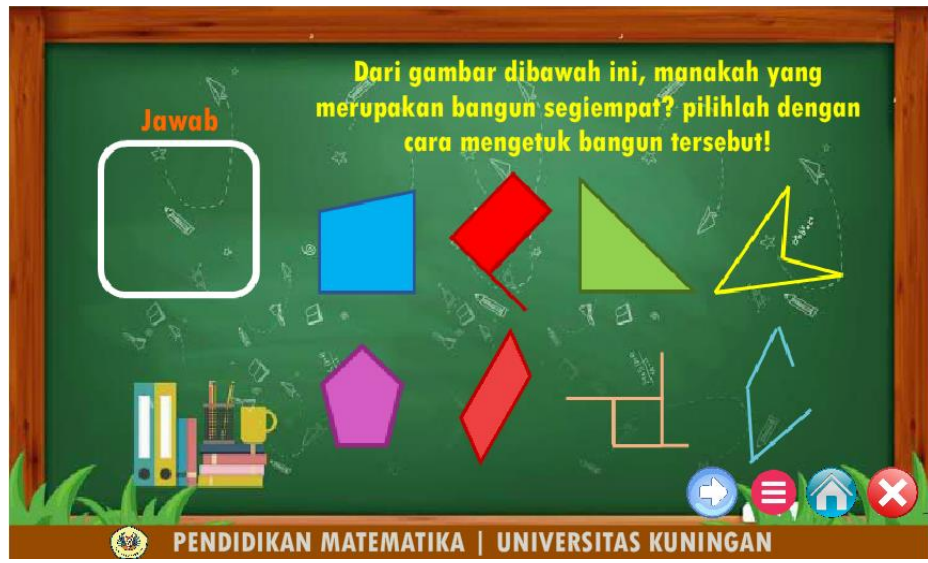

Gambar 1 Konstruktivisme

2. Bertanya dapat dilihat disetiap kegiatan pembelajaran. Hal ini karena menurut
Zaenab (2010) setiap informasi baru sealu diawali dengan bertanya. 


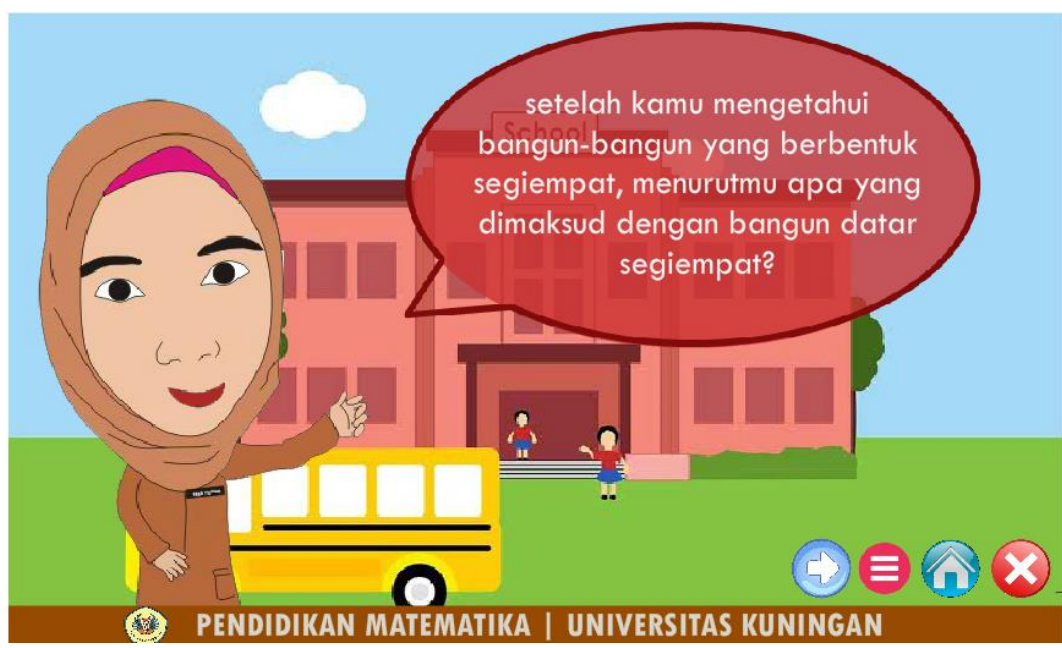

Gambar 2 Bertanya

3. Pemodelan dalam memperagakan contoh suatu proses pembelajaran. dapat ditiru oleh setiap siswa dalam

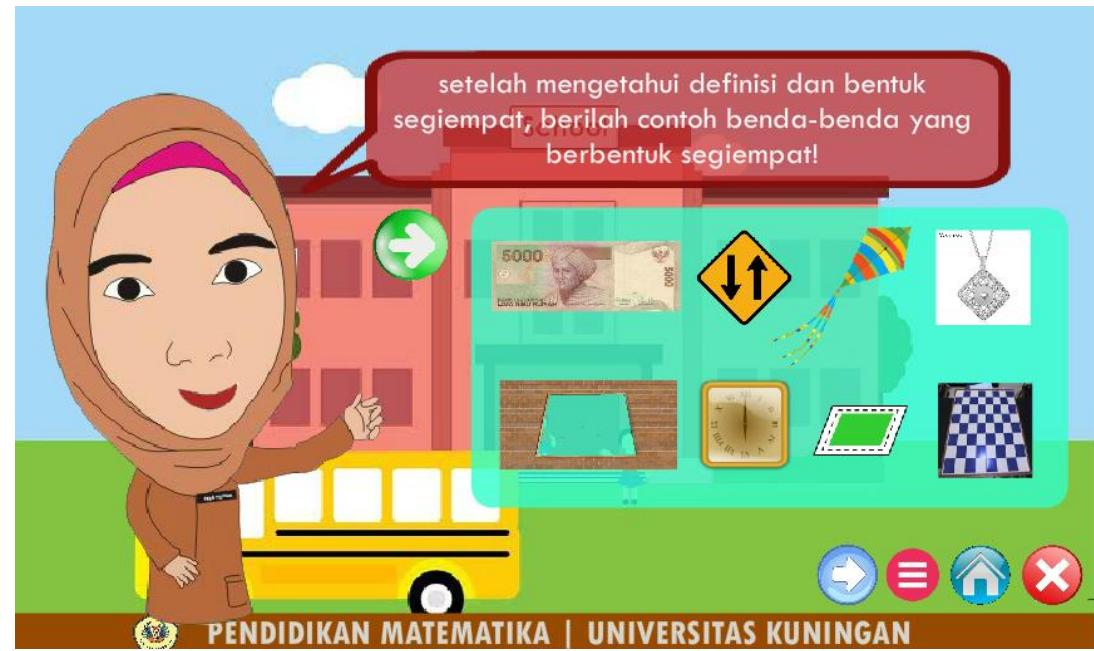

Gambar 3 Pemodelan

Penemuan merupakan cara memperoleh pengetahuan dengan menemukan sendiri agar pembelajaran lebih bermakna (Zaenab, 2010). Gambar di bawah ini adalah kegiatan untuk menemukan sifat dari jajargenjang berdasarkan sisinya. 


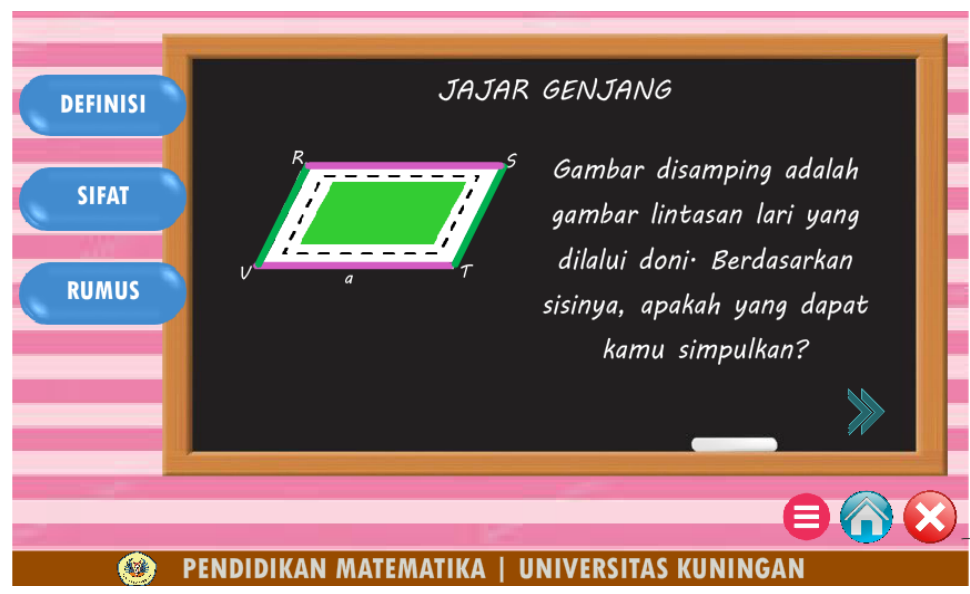

Gambar 4 Penemuan

5. Masyarakat Belajar menurut Zaenab (2010) merupakan kegiatan siswa dalam bekerja secara berkelompok untuk memperoleh pengetahuan dan menyelesaikan suatu masalah.

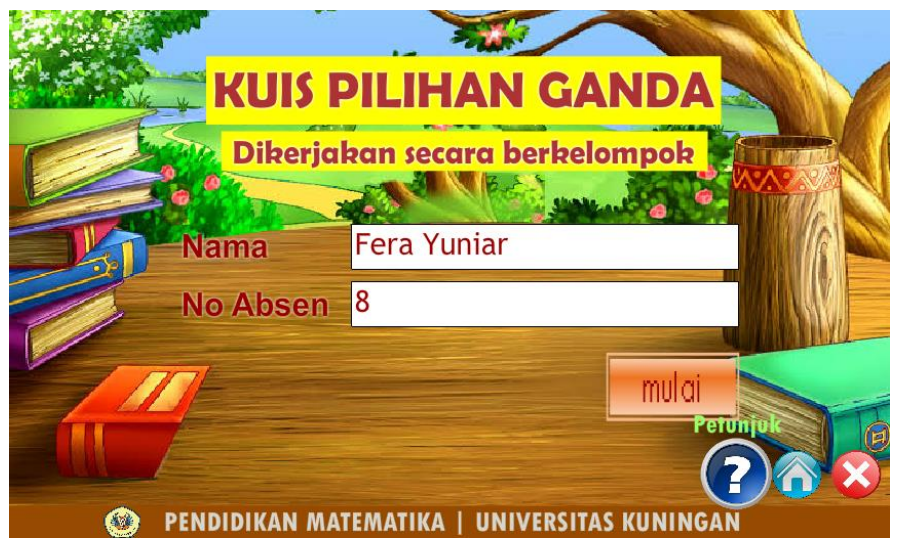

Gambar 5 Masyarakat Belajar

6. Penilaian Autentik merupakan suatu penilaian yang dilakukan guru kepada siswa dalam suatu proses pembelajaran.
Gambar di bawah ini adalah kegiatan penilaian autentik ketika siswa mengerjakan kuis pada media

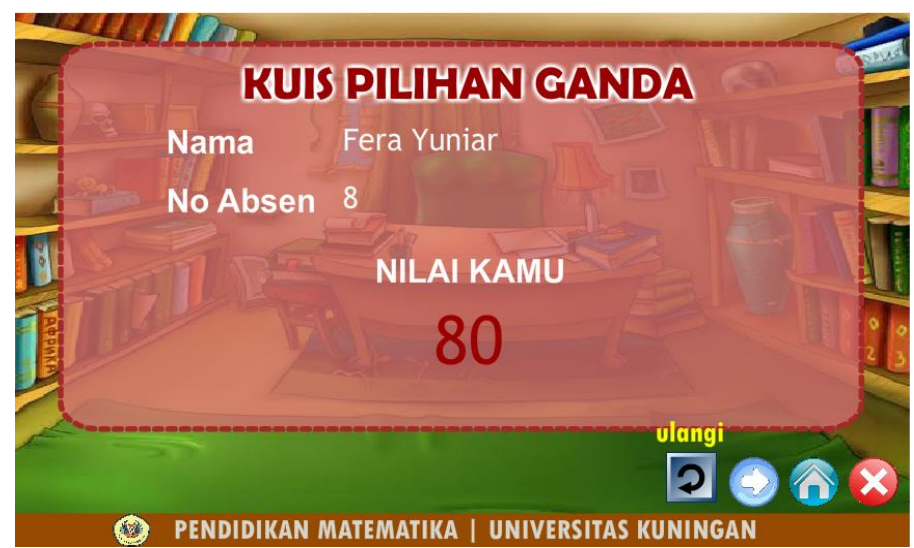

Gambar 6 Penilaian Autentik 
Refleksi ditampilkan pada akhir pembelajaran. hal ini karena menurut Zaenab (2010) untuk memberikan kesempatan kepada siswa untuk mencerna, menimbang dan menghayati tentang sesuatu yang baru dipelajari sehingga siswa dapat menyimpulkan pembelajaran yang didapatkan pada pertemuan tersebut dan disampaikan kepada siswa untuk mengkonfirmasi kebenaran dari pendapatnya tersebut.

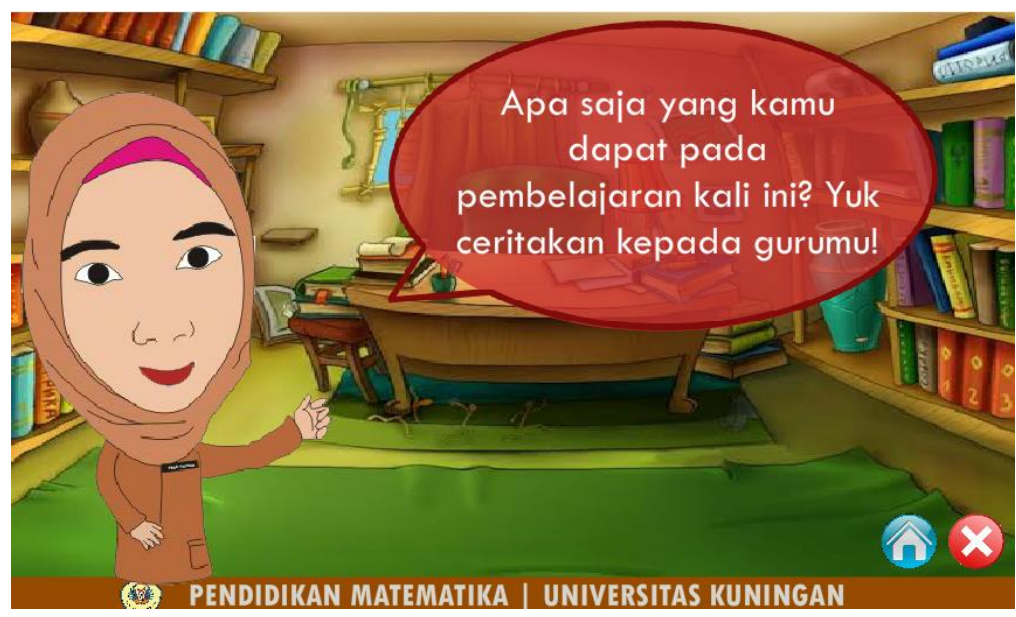

Gambar 7 Refleksi

\section{Kevalidan Media Pembelajaran}

Media pembelajaran divalidasi oleh tiga orang validator diantaranya dua orang dosen dan satu orang guru matematika. Tujuan dari uji validasi menurut Putri dkk.
(2014) adalah untuk mendapatkan validitas dari media yang dikembangkan dalam bentuk prototype I. Adapun hasil penilaian validator terhadap media pembelajaran yang dikembangkan adalah sebagai berikut:

Tabel 2. Validasi Media Pembelajaran

\begin{tabular}{lcccc}
\hline \multirow{2}{*}{\multicolumn{1}{c}{ Aspek }} & \multicolumn{3}{c}{ Validator } & Hasil Rata- \\
\cline { 2 - 4 } & $\mathbf{1}$ & $\mathbf{2}$ & $\mathbf{3}$ & Rata \\
\hline Isi Media & 3,6 & 4,0 & 2,7 & 3,4 \\
Instruksional & 3.4 & 3,2 & 3,0 & 3,2 \\
Teknis & 3,5 & 3,3 & 3,0 & 3,3 \\
Isi Materi & 3,8 & 3,8 & 3,0 & 3,5 \\
Pembelajaran & 3,7 & 3,2 & 3,2 & 3.4 \\
Karakteristik Model Pembelajaran & 3,3 & 3,0 & 3,3 & 3.2 \\
Contextual Teaching and Learning & \multicolumn{2}{c}{3,0} & 3,5 \\
Indikator Kemampuan Koneksi Matematis & 4,0 & 3,0 & 3,4 & \multirow{3}{*}{$\mathbf{3 , 4}$} \\
\hline Rata-rata & $\mathbf{3 , 6}$ & $\mathbf{3 , 4}$ & $\mathbf{3 , 1}$ & \\
\hline Total Rata-rata (VR) & \multicolumn{3}{c}{} \\
\hline
\end{tabular}

Berdasarkan tabel 2 diketahui bahwa hasil rata-rata dari validator pertama sebesar 3,6 dan validator kedua sebesar 3,4 serta validator ketiga sebesar 3,1. Maka nilai rata-rata dari ketiga validator terhadap media pembelajaran yang dikembangkan 
sebesar 3,4, artinya menurut Fithryah (2018) media pembelajaran masuk pada kategori valid sehingga dapat digunakan dalam pembelajaran.

\section{SIMPULAN DAN SARAN}

\section{Simpulan}

Simpulan dari penelitian ini adalah sebagai berikut: 1) prosedur pengembangan media pembelajaran berbasis adobe flash CS6 dilakukan dengan menggunakan model pengembangan plomp yang mana model pengembangan ini memiliki tiga fase, yaitu preliminary research, prototyping phase, dan assessment phase, 2) Media pembelajaran yang dikembangkan berada dalam kategori valid dengan berdasar pada penilaian yang diberikan oleh tiga orang validator yang diantaranya dua orang dosen dan satu orang guru

\section{Saran}

Penelitian pengembangan media pembelajaran segiempat berbasis adobe flash CS6 ini memiliki beberapa keterbatasan, sehingga agar media pembelajaran ini menjadi lebih baik dimasa yang akan datang perlu dilakukan penelitian-penelitian sejenis, dengan ini penulis menyarankan: 1) Penelitian dengan menggunakan soal-soal kemampuan koneksi matematis pada media pembelajaran segiempat yang dikembangkan untuk selanjutnya disarankan dapat dilakukan lagi dengan menggunakan materi pelajaran lainnya, 2) Media pembelajaran yang dikembangkan selanjutnya disarankan untuk mempunyai kategori tinggi dan sangat valid sehingga dapat dengan tepat digunakan dalam pembelajaran, 3) Media pembelajaran yang dikembangkan selanjutnya disarankan untuk dapat masuk pada kategori praktis dan mendapatkan respon yang baik dari guru maupun siswa, 4) Bagi peneliti selanjutnya apabila mengembangkan media pembelajaran segiempat berbasis adobe flash CS6 disarankan penelitiannya dapat dilanjutkan sampai tahap uji lapangan, sehingga data yang didapatkan untuk mengetahui kevalidan lebih akurat.

\section{DAFTAR PUSTAKA}

Fitrhiyah, A. I. (2018). Pengembangan Perangkat Pembelajaran Matematika Berbasis Warisan Budaya Indonesia untuk Melatihkan Literasi Matematis Siswa. (Skripsi). Universitas Islam Negeri Sunan Ampel Surabaya, Surabaya

Jalaludin, M., Rohaeti, E. E., \& Afrilianto, M. (2018). Analisis Kemampuan Koneksi Matematis Siswa MTs Kelas VII pada Materi Segitiga dan Segiempat. Jurnal Pembelajaran Matematika Inovatif, 1(4), 695-702.

Kemendikbud. (2016). Permendikbud Nomor 20 tentang Standar Kompetensi Lulusan Pendidikan Dasar dan Menengah

Kemendikbud. (2018). Permendikbud Nomor 35, tentang Perubahan Atas Peraturan Menteri Pendidikan Dan Kebudayaan Nomor 58 Tahun 2014 Tentang Kurikulum 2013 Sekolah Menengah Pertama/Madrasah Tsanawiyah

Kurnia, A. I. 2019. Pengembangan Media Pembelajaran Segiempat Berbantuan Adobe Flash dengan Menggunakan Model Discovery Learning untuk meningkatkan Kemampuan Representasi Matematis. (Skripsi). Universitas Kuningan, Kuningan

Lestari, K..E. dan Yudhanegara, M.R. (2015). Penelitian Pendidikan Matematika. Bandung: Refika Aditama.

Mauliana, Ikhsan, M., \& Subianto, M. (2018). Development of Learning 
Tool with Contextual Teaching and Learning ( CTL ) Approach to Improve Student Mathematical Connection Ability Development of Learning Tool with Contextual Teaching and Learning ( CTL ) Approach to Improve Student Mathematical Conn. Journal of Physics.

Musriliani, C., Marwan, \& Anshari, B. I. (2015). Pengaruh Pembelajaran Contextual Teaching Learning (CTL) terhadap Kemampuan Koneksi Matematis Siswa SMP Ditinjau dari Gender. Jurnal Didaktik Matematika, 2(2), 49-58.

Nugroho, R. S. A. (2011). Keefektifan Pembelajaran Matematika dengan Menggunakan Kombinasi Media CD Interaktif fan Lembar Kerja Peserta Didik Terhadap Hasil Belajar Matematika Dalam Materi Garis Singgung Lingkaran di SMP N 3 Cepiring. (Skripsi), Institut Agama Islam Negeri Walisongo.

Nurfitria, Bambang, H., \& Asep, N. (2013). Kemampuan Koneksi Matematis Siswa Ditinjau dari Kemampuan Dasar Matematika di SMP. [online]. Tersedia

https://scholar.google.com/scholar?hl= id\&as_sdt=0\%2C5\&q=Kemampuan+ koneksi+matematis+siwa+ditinjau+da ri++kemampuan+dasar+matematika+d $\mathrm{i}+\mathrm{SMP} \& \mathrm{btnG}=\# \mathrm{~d}=\mathrm{gs} \_q a b s \& \mathrm{u}=\% 23 \mathrm{p}$ \%3DJfzEsCz4ktEJ

Panjaitan, D. J. (2016). Penerapan pendekatan Contextual Teaching and Learning (CTL) untuk Meningkatkan hasil Belajar Statistika. Mathematics Pedagogic, 1(1), 1-10.

Plomp, T., \& Nieveen, N. (2013). An Introduction to Educational Design Research.

Purwanti, B. (2015). Pengembangan Media Video Pembelajaran Matematika dengan Model Assure. Jurnal
Kebijakan Dan Pengembangan Pendidikan, Vol.3, No.1.

Puspita, E. J. L. (2016). Pengembangan Media Komputer Berbasis Adobe Flash CS5 Untuk Membantu Pemahaman Konsep Segiempat di Kalangan Siswa SMP Negeri 15 Yogyakarta. (Skripsi), Universitas Sanata Dharma.

Putri, N. W. S., Sariyasa, \& Ardana, I. M. (2014). Pengembangan Perangkat Pembelajaran Tandur Berbantuan Geogebra sebagai Upaya Meningkatkan Prestasi dan Aktivitas Belajar Geometri Siswa. E-Jurnal Program Pasca Sarjana Universitas Pendidikan Indonesia, 3.

Rahmawati, S. A., Hobri, \& Oktavianingtyas, E. (2015). Analisis Kemampuan Koneksi Matematis pada Pokok Bahasan Statistika Berbasis Lesson Study For Learning Community. Kadikma, 2(2), 41-51.

Rinzani, A. R. (2017). Kemampuan Koneksi Matematis Peserta Didik Melalui Pendekatan Advokasi Dengan Penyajian Masalah Open-Ended di SMP N 5 Terbanggi Besar. (Skripsi), Universitas Islam Negeri Raden Intan Lampung.

Widada, W. (2015). Process of Achieving Mathematical Concepts by Utilizing Contextual Learning Media. Journal of Mathematics Education and Science, Vol. 22, No. 1, March 2015: 31-44

Yuniawati, L. D., \& Zuhrie, M. S. (2019). Pengembangan Media Pembelajaran Multimedia Interaktif pada Mata Pelajaran Penerapan Sistem Radio dan Televisi di SMK Negeri 3 Surabaya. Jurnal Pendidikan Teknik Elektro, 8(2), 161-167.

Zaenab, D. K. (2010). Pengaruh Pembelajaran Kontekstual Terhadap Kemampuan Koneksi Matematis Siswa. (Skripsi), Universitas Islam Negeri Syarif Hidayatullah. 
